\title{
A dos manos: Creación de material didáctico signado mediante aprendizaje-servicio
}

\section{At two hands: creation of teaching material signed through learning-service}

\author{
María Josefa Vilches ${ }^{1}$, María del Carmen Trillo², María del Mar Molina, ${ }^{3} \&$ María \\ Elena Pedraza ${ }^{4}$
}

Fecha de recepción: 07/10/2019; Fecha de revisión: 16/01/2020; Fecha de aceptación: 20/02/2020

Cómo citar este artículo:

Vilches, M. J., Trillo, M. C., Molina, M. M., \& Pedraza, M. E. (2020). A dos manos: Creación de material didáctico signado mediante aprendizaje-servicio. Revista de Innovación y Buenas Prácticas Docentes, 9(1), 42-52.

Autor de Correspondencia: fe1vivim@uco.es

\section{Resumen:}

La Universidad ha de afrontar el compromiso social que la caracteriza respondiendo a las necesidades de su entorno. El aprendizaje-servicio es una metodología que promueve la acción social desde las aulas, aunando principios pedagógicos fundamentales como el de experiencia, el de participación y el altruismo. En este trabajo se presenta "A dos manos", un proyecto de innovación desarrollado por el alumnado matriculado en tres asignaturas optativas de $4^{\circ}$ de los Grados en Educación Infantil y en Educación Primaria del Centro de Magisterio Sagrado Corazón, que ha sido realizado en colaboración con las y los cotutores del CEIP Colón. La finalidad de la experiencia es facilitar a estos docentes que atienden a escolares con discapacidad auditiva una colección de recursos interactivos en línea creados con la aplicación Genially. Se trata de láminas ilustradas en las que se reúne el vocabulario que aparece en los libros de texto utilizados por los niños y niñas en varias lenguas (español, inglés y lengua de signos española), con el propósito de ampliar y afianzar su léxico.

Palabras clave: innovación pedagógica, lenguaje de signos, tecnología de la educación, enseñanza superior

\begin{abstract}
:
Universities must face the social commitment that characterizes them, in order to answer the needs of its environment. The learning-service is a methodology that promotes social action in the classroom, joining fundamental pedagogical principles such as experience, participation and altruism. "At two hands" is presented as an innovative project developed by the fourth-year students of the "Sagrado Corazon" University, who are enrolled in three optional subjects, and may be from the Primary or Preschool Education degree course. The Project has also been developed in association with the tutors from "Colon School". The purpose of this experience is to make the work of teachers who deal with deaf students easier, using a collection of interactive resources which will be available to them. It has been designed with the Genially application, including illustrated sheets in which the vocabulary of the text books that are used by the kids appear. These sheets will be in three different languages; Spanish, English and Spanish signal language with the purpose of increasing and reinforcing students' vocabulary.
\end{abstract}

Key Words: educational innovation, sign language, educational technology, higher education

\footnotetext{
${ }^{1}$ Universidad de Córdoba (España), fe1vivim@uco.es; CÓDIGO ORCID: https://orcid.org/0000-0002-2791-4879 2Universidad de Córdoba (España), fe1trlum@uco.es; CÓDIGO ORCID: https://orcid.org/0000-0002-8990-1504 ${ }^{3}$ CEIP Colón, Córdoba (España), marmolinaherrera@gmail.com

${ }^{4}$ CEIP Colón, Córdoba (España), pedrazamariaelena14@gmail.com
} 


\section{INTRODUCCIÓN}

En la última década del pasado siglo, en los sistemas educativos de los países de nuestro entorno, comenzaron a desarrollarse modelos centrados en la enseñanza a partir de la lengua de signos, redefiniendo el concepto de sordera y erigiéndose esta lengua como un rasgo cultural de las comunidades sordas. La Ley 17/2007, de 10 de diciembre, de Educación de Andalucía (LEA), en el artículo 113, apartado 8, pionera en este sentido, señala expresamente que "la escolarización del alumnado sordo durante la enseñanza básica se llevará a cabo, preferentemente, en centros que dispongan de intérpretes de lengua de signos española u otros medios técnicos como recursos específicos" (p. 23). Por su parte, la Ley Orgánica 2/2006, de 3 de mayo, de Educación (LOMCE), en su artículo 79 bis, 2 manifiesta que "la escolarización del alumnado que presenta dificultades de aprendizaje se regirá por los principios de normalización e inclusión, y asegurará su no discriminación y la igualdad efectiva en el acceso y permanencia en el sistema educativo" (p. 97896), que en el caso del alumnado sordo, debe contemplar la posibilidad de utilizar la lengua de signos española (LSE) como lengua vehicular, si sus padres o tutores legales así lo desean.

A este respecto, se ha de tener en cuenta que son niños y niñas con necesidades específicos de apoyo educativo (NEAE) que muestran dificultades en vocabulario, habilidades metafonológicas y de acceso al léxico (Carrero, 2017), lo que influye en su aprendizaje y requiere que se proporcione en contextos educativos una atención a la diversidad acorde a sus necesidades.

En este sentido, el CEIP Colón, situado junto a los céntricos jardines que llevan el mismo nombre, ofrece una respuesta educativa adecuada para el alumnado sordo. Tradicionalmente ha sido un centro de integración de escolares con discapacidad auditiva que hasta la última década seguía un enfoque comunicativo oralista con este tipo de estudiantes. Es a partir del curso 2006/07 cuando comienza a introducir la lengua de signos en la enseñanza, pero no es hasta cuatro años después cuando articula formalmente su propuesta, estando en la actualidad declarado como centro bilingüe de sordos (lengua castellana/lengua de signos española). El centro cuenta con la figura del maestro/a cuyo perfil profesional es el de Audición y Lenguaje (AL) con alta competencia comunicativa en Lengua de Signos Española (LSE), que realiza una tutoría compartida en las aulas donde se encuentra incluido el alumnado sordo. Este profesorado tiene como misión atender a niños y niñas de Educación Infantil y Primaria con discapacidad auditiva en tres niveles de actuación (Molina y Pedraza, 2018):

- Nivel individual, se pone de manifiesto principalmente, en tres tipos de actuaciones: (1) proporcionar a las y los alumnos sordos de nuevo ingreso una competencia comunicativa en LSE que les permita organizar su pensamiento y sirva de instrumento de comunicación; (2) permitir el acceso al currículo a través de la lengua de signos; (3) adaptar material didáctico que facilite dicho acceso, mediante imágenes, mapas conceptuales, etc.

- Nivel de aula, traduciendo todo lo que se habla en esta a la LSE y haciendo llegar a los estudiantes lo que ocurre a su alrededor, permitiéndole participar plenamente en la vida de la clase, lo que favorece el desarrollo comunicativo en esta lengua no solo del alumnado con discapacidad auditiva, sino también del normo-oyente.

- Nivel de centro, centrado en sensibilizar a toda la comunidad educativa sobre las características de las personas sordas a través de la celebración de efemérides, carteles, letreros en LSE, etc., además de proporcionar formación 
e información al profesorado sobre las necesidades especiales de los escolares sordos.

Entre las dificultades que tienen las y los cotutoras/es para desarrollar su labor se encuentran la escasez de materiales adaptados a las necesidades específicas de apoyo educativo (NEAE), no solo en lo referido a la LSE, sino también a su forma particular de aprendizaje. No hay que olvidar que desde el ámbito de la neuropsicología se especifica la existencia de diferencias en la organización cerebral de los estudiantes sordos con la de sus compañeros y compañeras normo-oyentes, dado que aprenden de manera visual (Herrera-Fernández, 2014).

\section{DESARROLLO DE LA EXPERIENCIA DE INNOVACIÓN}

Ante esta necesidad, se plantea el Proyecto que aquí se describe, destinado a promover actuaciones para los que maestros y maestras en formación de los Grados en Educación Infantil y Primaria se conviertan en creadores de contenido, movilizando diversos tipos de aprendizajes:

- Competencias profesionales que les habiliten para diseñar espacios de aprendizaje en contextos de diversidad.

- Conocimientos pedagógicos referidos a las NEE de los niños y niñas con discapacidad auditiva.

- Competencias comunicativas básicas en LSE y la capacidad de aplicarlas en el aula.

- Competencias digitales que les capaciten para aprovechar las posibilidades didácticas que brindan las aplicaciones informáticas gratuitas disponibles.

- Habilidades sociales y cívicas, entrenando la capacidad de trabajar en equipo y en colaboración con profesionales experimentados y prestando un servicio a la comunidad.

- Sentido crítico respecto a que siempre serán insuficientes los recursos personales y materiales proporcionados por la administración educativa.

Ante lo mencionado, este Proyecto implicaría además, de la formación inicial de los futuros docentes, la promoción del aprendizaje de los estudiantes con discapacidad auditiva y un beneficio para su proceso de enseñanza-aprendizaje.

Se considera como beneficiarios de este Proyecto de innovación los colectivos siguientes:

- En primer lugar, 65 estudiantes de $4^{\circ}$ de los Grados en Educación Infantil y en Educación Primaria del Centro de Magisterio Sagrado Corazón que cursaban las asignaturas optativas "Lengua de signos española para una escuela inclusiva en Educación Infantil", "Estimulación y atención temprana en la primera infancia" y "Lengua de Signos en Educación Primaria". Todos ellos y ellas conocieron más profundamente las necesidades especiales del alumnado sordo y desarrollaron sus competencias profesionales para proporcionar una respuesta educativa de calidad aprovechando las posibilidades que ofrecen la Tecnologías de la Información y la Comunicación (TIC).

- En segundo lugar, los escolares con discapacidad auditiva y normo-oyentes de $2^{\circ}$ ciclo de Educación Infantil y 1er ciclo de Educación Primaria del CEIP Colón, que podrán acceder a los recursos generados en línea, por lo que podrán repasar el vocabulario que aparece en las unidades didácticas de sus libros de texto en español, inglés y LSE, tanto en el aula, como en casa.

- En tercer lugar, los docentes del CEIP Colón, que van a disponer de algunos recursos didácticos adaptados a las necesidades de estos niños y niñas basados en los textos escolares que estos utilizan.

- Por último, el profesorado responsable del proyecto, que ha mejorado su formación respecto a la temática que se aborda. 


\subsection{Objetivos del proyecto}

Para dar respuesta a la finalidad general del Proyecto, los objetivos que se han planteado son los siguientes:

- Establecer lazos de colaboración entre la universidad y los contextos reales en que los estudiantes de magisterio desarrollarán su profesión.

- Desarrollar en los maestros y maestras en formación competencias para la atención a la diversidad, conectando la teoría y la práctica respecto a las necesidades educativas de los escolares con discapacidad auditiva.

- Facilitar la labor educativa de los docentes que tienen en sus aulas niñas y niños sordos, proporcionándoles un banco de materiales educativos adaptados a los sordos signantes.

- Facilitar el acceso de los materiales adaptados a los escolares en cualquier momento y lugar, gracias al uso de las TIC.

\subsection{Material y métodos}

La metodología que subyace en el presente proyecto es la de Aprendizaje-Servicio (ApS), que como entienden Cerda, Graell, Martín, Muñoz y Puig (2009), se trata de un servicio solidario protagonizado por los estudiantes, cuya finalidad es dar respuesta a necesidades reales, planificando de forma integrada el currículo en función de sus aprendizajes. Basado en una concepción solidaria del mundo, el ApS pone de manifiesto principios pedagógicos fundamentales como el principio de experiencia, el de participación y el altruismo (Puig, 2015). Es una metodología muy enriquecedora en la formación inicial de los futuros maestros y maestras, dado que posibilita la conexión de su itinerario curricular con el servicio (Cotrina \& García, 2016). Además, de ser una buena opción para mejorar la formación de los estudiantes en atención a la diversidad (Liesa, Arranz \& Vázquez, 2013) y que favorece la educación inclusiva (González \& Zarzuela, 2016).

El equipo de trabajo que ha emprendido este Proyecto estuvo constituido por un grupo de personas pertenecientes al Centro de Magisterio Sagrado Corazón con funciones diversas: dos profesoras que desarrollaron la experiencia en las asignaturas antes mencionadas, una persona perteneciente al Personal de Administración y Servicios (PAS), que contribuyó al diseño de la páginas web que reúne los recursos elaborados por las y los estudiantes de magisterio y una alumna de $2^{\circ}$ del Grado en Educación Primaria que realizó labores de ilustradora.

También formaron parte del equipo de este Proyecto de innovación docente cinco cotutoras/es del CEIP Colón (Córdoba) que atienden a las y los alumnos con discapacidad auditiva dentro de su aula ordinaria utilizando la LSE como lengua vehicular, que orientaron a los futuros docentes sobre las necesidades educativas de los escolares que tienen a su cargo y un maestro sordo que asesoró sobre vocabulario y expresiones en lengua de signos con los que el alumnado de magisterio no estaba familiarizado.

\subsection{Fases de desarrollo del proyecto}

Inicialmente, este Proyecto fue diseñado para ser desarrollado en tres fases: preparación, implementación y evaluación del mismo. A continuación se describen cada una de ellas. 
En la primera de estas fases, dedicada a la preparación y coordinación del Proyecto, el profesorado participante de ambos centros mantuvo una reunión para priorizar el material a adaptar. Entre las decisiones que se tomaron fue adaptar el material para dos de los cursos en los que había más estudiantes sordos (Educación Infantil 4 años y $1^{\circ}$ de Primaria).

Por otro lado, dado que en el planteamiento inicial del Proyecto contemplaba que los recursos que crearían los estudiantes de magisterio estuvieran basados en los libros de texto que utilizaban los escolares, se contactó con las editoriales para solicitar permiso para reproducir algunas de las ilustraciones que aparecían en estos, pero no se llegó a un acuerdo, por lo que se decidió utilizar otras imágenes alternativas.

También en esta fase preparatoria, el alumnado de magisterio se desplazó al CEIP Colón para participar en una sesión formativa en la que dos cotutoras y algunos niñas y niños con discapacidad auditiva explicaron su experiencia con el proyecto bilingüe con LSE y enseñaron los materiales didácticos adaptados que se utilizaban.

La fase de implementación se dedicó a crear las láminas interactivas que se enriquecieron con vocabulario en distintas lenguas, que los estudiantes de magisterio crearon en grupos colaborativos. El proceso seguido, en esta fase, fue el siguiente:

1. Realización de un taller sobre aplicación Genially, en el aprendieron el funcionamiento básico de esta sencilla plataforma, como incluir imágenes, añadirles contenido interactivo, trabajar de forma colaborativa con ellas, general una enlace para compartirlas, etc.

2. Formación de equipos de trabajo y asignación de las unidades didácticas contenidas en los libros de texto escolares a cada grupo.

3. Análisis y selección del vocabulario básico contenido en las mencionadas unidades didácticas.

4. Búsqueda de las imágenes idóneas que pudieran recoger el vocabulario seleccionado.

5. Aprendizaje del vocabulario y las expresiones signadas, grabación en vídeo y alojamiento en la plataforma en línea YouTube.

6. Creación de las imágenes interactivas con Genially, insertando contenidos de lenguas (español e inglés y LSE) (véase la Figura 1). Tras finalizar la elaboración del recurso digital, los estudiantes lo compartieron con las profesoras.

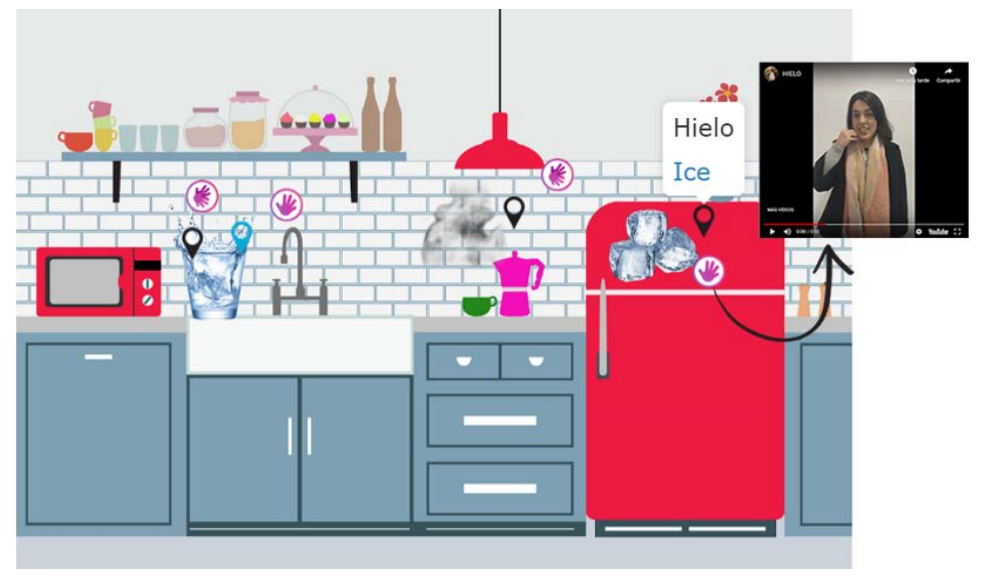

Figura 1. Detalle de una lámina tras pulsar los botones de interactividad.

Fuente: Elaboración propia.

La última fase se dedicó a la evaluación del Proyecto. Por un lado, el alumnado de magisterio cumplimentó una breve escala de valoración realizada Typeform, que tiene la doble ventaja que puede ser compartida a través de mensajería instantánea y permite descargar los resultados en una hoja de cálculo Excel. 
Por otra parte, también se recogió la opinión del profesorado implicado de ambos centros educativos con vistas a realizar propuestas de mejora.

\section{RESULTADOS}

En relación a los recursos digitales generados, podemos decir que se han elaborado más de 30 presentaciones con Genially compuestas cada una de ellas por varias láminas interactivas.

El alumnado de la asignatura "Lengua de signos para una escuela inclusiva en Educación Infantil" trabajó sobre unos libritos informativos que formaban parte del material curricular que utilizaban los niños y niñas de 4 años, destinados a que conocieran las culturas de distintos países: Japón, México, Kenia y París. Los estudiantes de "Lengua de signos en Educación Primaria" se centraron en la generación de recursos para $1^{\circ}$ de Primaria de Ciencias Sociales (la casa y la familia, el barrio, los transportes, etc.) y Ciencias Naturales (el cuerpo, los animales, las plantas, las máquinas, etc.). Por último, los alumnos y alumnas de "Estimulación y atención temprana en la primera infancia", elaboraron un programa de atención para la etapa de Educación Infantil, cuyas actividades fueron adaptadas para los escolares sordos, por lo que se han creado recursos, con temáticas como las emociones, el tiempo cronológico, los hábitos de higiene personal, las partes del cuerpo y los sentidos, el colegio, etc.

Finalmente, para facilitar el acceso y la consulta a estos recursos, se han recopilado en una página web que se diseñó con la aplicación Wix (véase la Figura 2).

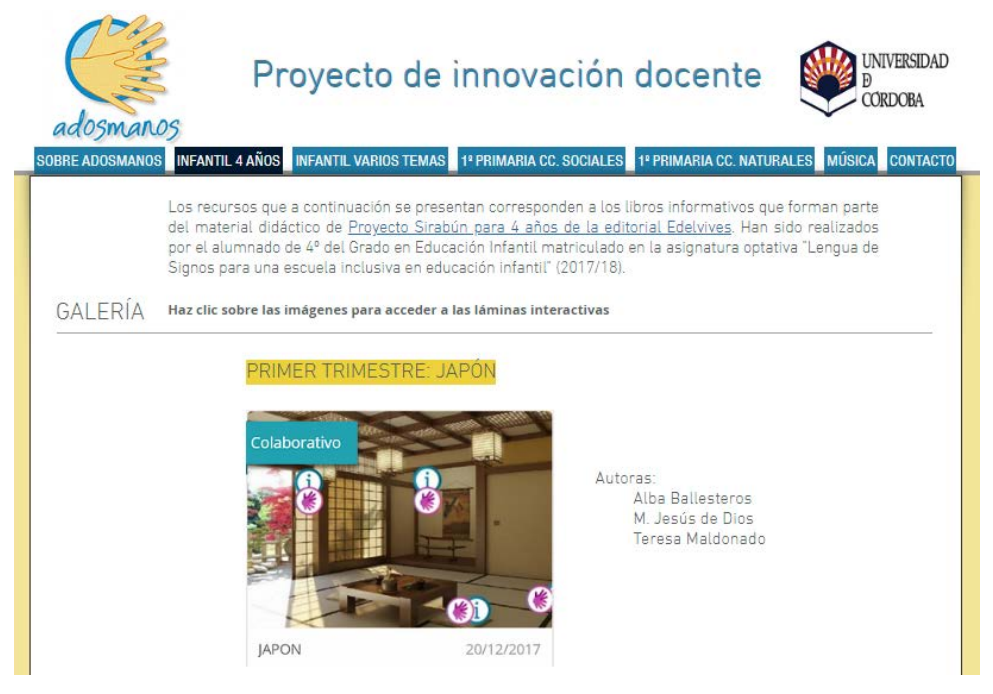

Figura 2. Página web sobre el Proyecto A dos manos.

Recuperado de https://pvilchesv.wixsite.com/adosmanos

Como se comentó anteriormente, los estudiantes de magisterio cumplimentaron una pequeña escala de valoración anónima compuesta por seis ítems respecto a su participación en el Proyecto "A dos manos". De los 65 estudiantes matriculados en las asignaturas antes mencionadas, completaron el cuestionario 43, los cuales estimaron de 1 a 10 cada uno de los ítems, que posteriormente se recodificaron en cuatro 
apreciaciones: Muy buena (9-10 puntos), Buena (7-8 puntos), Regular (4-6 puntos) y Deficiente (0-3 puntos).

El primero de los ítems (Conocimiento sobre la finalidad del proyecto (objetivos y destinatarios), intentaba valorar si eran conscientes de que el Proyecto transcendía los límites de su aula e iba destinado a niños y niñas con unas necesidades reales. Como se puede observar en la Figura 3, la mayoría de estos valoraron este conocimiento como muy bueno (62\%) o bueno (22\%). Solo el $2 \%$ estimaron que desconocían la finalidad del "A dos manos".

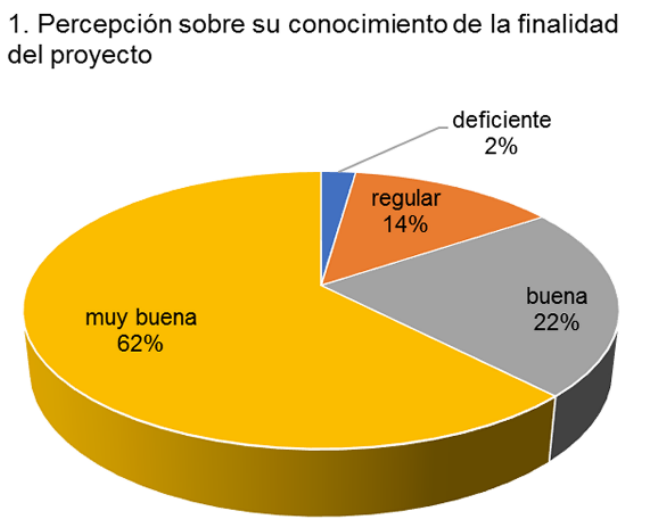

Figura 3. Valoración de los estudiantes de magisterio sobre su conocimiento de la finalidad de "A dos manos".

El segundo de los ítems (Las indicaciones proporcionadas para la elaboración del recurso didáctico -qué hay que hacer- han sido suficientes) pretendía valorar si los guiones de trabajo y las orientaciones proporcionadas por el profesorado para realizar la actividad marcaban las pautas necesarias para desarrollarla con éxito. También en este caso, la mayoría de los estudiantes (82\%) manifestaron su satisfacción (véase la Figura 4), considerando que estas orientaciones fueron muy buenas (62\%) y buenas (20\%), aunque para una parte de estos resultó mejorable (18\%).

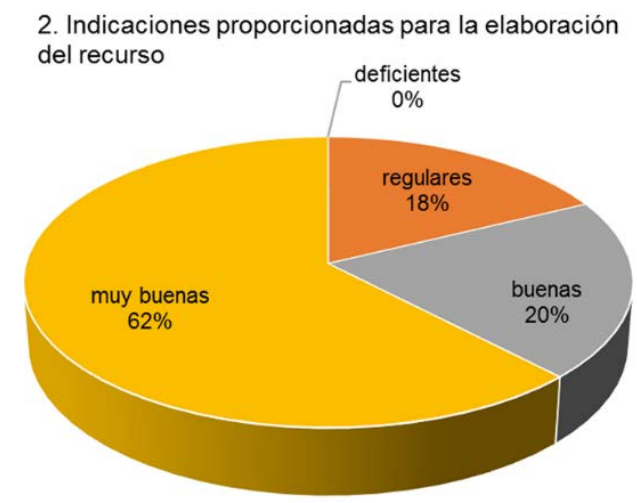

Figura 4. Valoración de los estudiantes de magisterio sobre las orientaciones proporcionadas por el profesorado para realizar sus recursos.

El tercer ítem (El tiempo facilitado en clase para la elaboración del recurso didáctico ha estado ajustado a su dificultad) iba encaminado a considerar si la temporalización prevista para la creación de las imágenes interactivas era acorde las acciones que 
tenían que realizar. Como se refleja en la Figura 5, gran parte del alumnado valoró muy favorablemente este ítem, ya que estimó que el tiempo estuvo ajustado a la dificultad de la tarea, considerando la valoración como muy buena (67\%) o buena (20\%). El $11 \%$ la consideró susceptible de mejora y solo el $2 \%$ apreció que la estimación del tiempo calculada fue deficiente.

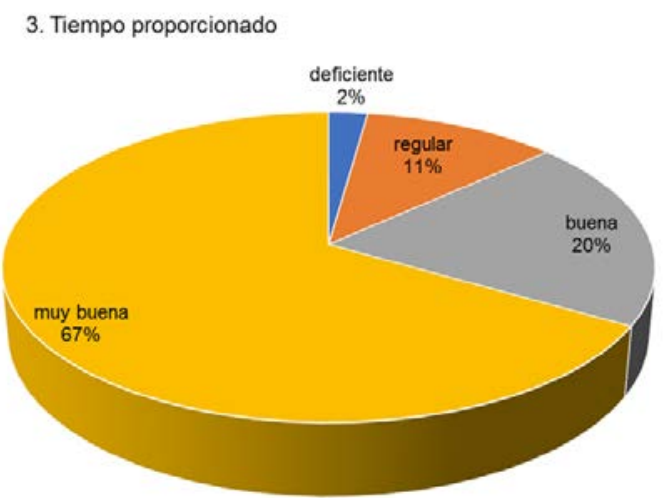

Figura 5. Valoración de los estudiantes de Magisterio sobre el tiempo proporcionado para realizar la tarea.

El cuarto ítem (se me ha proporcionado la formación necesaria: taller de Genially, vocabulario signado a incluir, etc., para contribuir eficazmente con mi recurso al proyecto) tenía como finalidad valorar la utilidad del taller sobre la aplicación Genially, además de las orientaciones proporcionadas por el profesorado y el asesor sordo sobre el vocabulario y expresiones en LSE desconocidas por los alumnos y alumnas (que se grabaron en vídeo) eran suficientes para que pudieran realizar sus imágenes interactivas. También en este caso la valoración fue positiva, considerando el $71 \%$ como muy buena y el $27 \%$ buena (véase la Figura 6 ).

\section{Formación recibida}

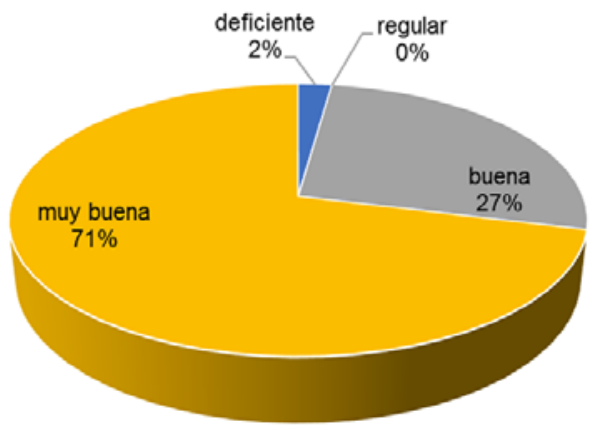

Figura 6. Valoración de los estudiantes de magisterio sobre la formación recibida respecto al uso de Genially y el asesoramiento en LSE. 
El quinto ítem (la visita realizada al CEIP Colón ha contribuido a conocer las necesidades educativas de los escolares con discapacidad auditiva), intentaba estimar su impresión sobre lo aprendido en la sesión formativa impartida en esta salida. Como se ve reflejado en la Figura 7, la casi totalidad de los encuestados valoró la visita como muy buena (82\%) y buena (16\%).

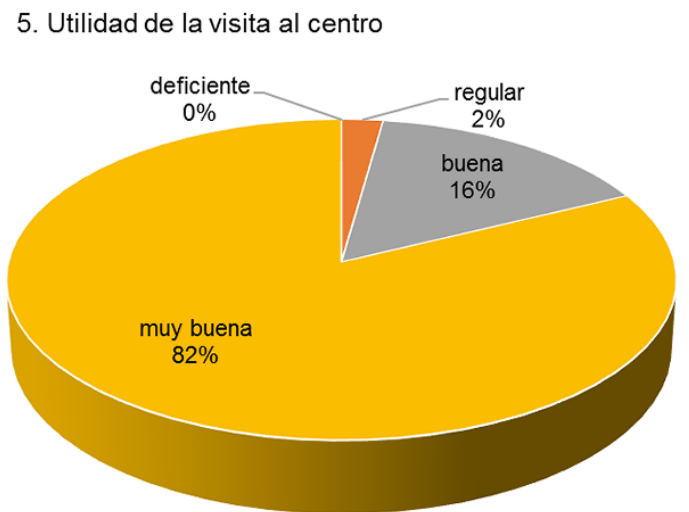

Figura 7. Valoración de los estudiantes de magisterio sobre la visita al CEIP Colón.

Por último, el sexto ítem (Estoy satisfecho globalmente con mi participación en el proyecto), como puede contemplarse en la Figura 8, los futuros docentes han valorado su satisfacción entre muy buena (82\%) y buena (16\%).

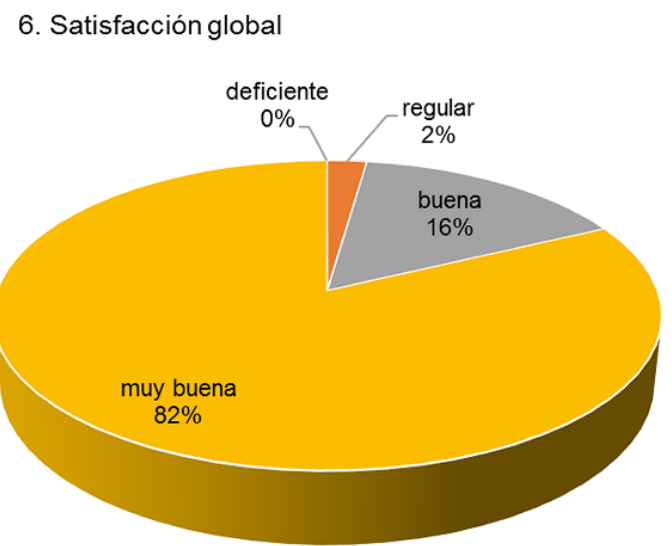

Figura 8. Valoración de los estudiantes de magisterio sobre su satisfacción global en respecto al Proyecto "A dos manos".

Respecto a la opinión del profesorado participante en "A dos manos", este está satisfecho en general con el Proyecto, aunque entre los aspectos que se pueden mejorar se citan los siguientes:

- Sustituir algunos vídeos en los que la realización de la LSE no proporciona un buen modelo lingüístico adecuado para los escolares por contener errores en la realización algunos de los parámetros formativos de los signos.

- Proporcionar a los estudiantes de magisterio indicaciones más precisas que mejoraran la calidad de los vídeos signados: fondo en color claro y uniforme, buena iluminación, plano de encuadre (plano medio largo o americano), 
vestimenta oscura, ausencia de objetos que distraigan (bufandas, pulseras, etc.), etc.

- Insistir en la utilización de imágenes de libre uso u originales realizadas por los propios alumnos y alumnas de magisterio.

\section{CONCLUSIONES}

El proyecto "A dos manos", se concibe como una herramienta válida para promover en los estudiantes de los títulos de Grado en Educación Infantil y en Educación Primaria, una mayor sensibilidad hacia las personas con NEAE, especialmente en el alumnado sordo, además de un mejor conocimiento y comprensión de sus características y necesidades. A su vez, permite que los futuros docentes completen su formación y desarrollen competencias para la atención a la diversidad (Liesa, Arranz \& Vázquez, 2013), tan importante y necesaria en el profesorado, elemento fundamental en el proceso de enseñanza-aprendizaje de los niños y niñas.

En relación al aprendizaje-servicio, esta metodología innovadora, permite no solo que el alumno conecte la teoría con la práctica, sino que este ofrezca una respuesta adecuada a la realidad (Graell, Martín, Muñoz \& Puig, 2009), provocando un aprendizaje en la realización del servicio y, por tanto, enriqueciendo su formación inicial (Cotrina \& García, 2016). Se considera, también, una posibilidad para el fomento y adquisición de competencias transversales universitarias, como el trabajo en equipo y la competencia digital, así como, la promoción de actitudes solidarias y altruistas (Puig, 2015).

Respecto a los docentes del CEIP Colón y a los escolares sordos, es evidente que el Proyecto redundará en ambos colectivos, por una parte, al mejorar y facilitar la labor del profesorado en su atención a estos niños y niñas sordas en el contexto educativo. Por otra parte, se obtendrá beneficios importantes en cuanto a su aprendizaje, al contar con recursos adaptados que facilitan su desarrollo comunicativo y su proceso lecto-escritor.

\section{AGRADECIMIENTOS}

Este Proyecto fue apoyado por la Universidad de Córdoba, en el marco del Plan de Innovación Docente para el curso 2017/2018 ( $n^{\circ}$ de proyecto 2017-4-4010 de la modalidad 4 "Proyectos que impulsen la colaboración con centros docentes públicos no universitarios"). Los autores también agradecen a los estudiantes de los Grados en Educación Infantil y en Educación Primaria participantes por la cesión de los recusos didácticos creados.

\section{REFERENCIAS}

Carrero, F. J. (2017). La comprensión lectora en el alumnado sordo desde la perspectiva de la Escuela Inclusiva. International Journal of Educational Research and Innovation (IJERI), 8, 200-219. Recuperado de http://hdl.handle.net/10433/5312

Cerda, M. de la, Graell, M., Martín, X., Muñoz, A., \& Puig, J. M. (2009).Aprendizaje servicio: Ejemplos y definiciones. En J. M. Puig (Coord.), Aprendizaje Servicio (ApS): Educación y compromiso cívico (pp. 15-32). Barcelona, España: Graó.

Cotrina, M. J., \& García, M. (2016). Aprendizaje y Servicio en cascada en la formación inicial del profesorado. En M. A Santos, A. Sotelino y M. Lorenzo (Coords.), Aprendizaje-Servicio e innovación en la universidad, Actas VII Congreso Nacional y II Internacional de Aprendizaje-Servicio Universitario (pp. 177-183). 
Recuperado

http://www.upv.es/entidades/CCD/infoweb/ccd/info/U0734813.pdf

González, E., \& Zarzuela, A. (2016). Apoyos para el desarrollo de una Educación Infantil inclusiva. En M. A Santos, A. Sotelino y M. Lorenzo (Coords.), Aprendizaje-Servicio e innovación en la universidad. Actas VII Congreso nacional y II internacional de aprendizaje-servicio universitario (pp. 338-338). Recuperado http://www.upv.es/entidades/CCD/infoweb/ccd/info/U0734813.pdf

Herrera-Fernández, V. (2014). Alfabetización y bilingüismo en aprendices visuales: Aportes desde las epistemologías de sordos. Educación y Educadores, 17(1), 135-148.

Recuperado

http://educacionyeducadores.unisabana.edu.co/index.php/eye/article/view/3107

Ley 17/2007, de 10 de diciembre, de Educación de Andalucía. Boletín Oficial de la Junta de Andalucía, 252, de 26 de diciembre de 2007.

Ley Orgánica 8/2013, de 9 de diciembre, para la mejora de la calidad educativa. Boletín Oficial del Estado, 295, de 10 de diciembre de 2013.

Liesa, M., Arranz, P., \& Vázquez, S. (2013). Un programa basado en la metodología del aprendizaje servicio que mejora las actitudes de los estudiantes del grado de Magisterio hacia la inclusión. Revista Interuniversitaria de Formación del Profesorado, 27(1), 65-82. Recuperado de https://www.redalyc.org/articulo.oa?id=27430137005

Molina, M. del M. y Pedraza, M. E. (2018). Proyecto bilingüe (lengua de signos lengua oral) en el CEIP Colón de Córdoba". En M. I. Amor, M. Osuna, \& E. Pérez (Eds.), Fundamentos de enseñanza y aprendizaje para una educación universal, intercultural y bilingüe (pp. 175-180). Barcelona, España: Octaedro.

Puig, J. M. (Coord.) (2015). ¿Cómo realizar un proyecto de aprendizaje servicio?: 11 ideas clave. Barcelona, España: Graó. 